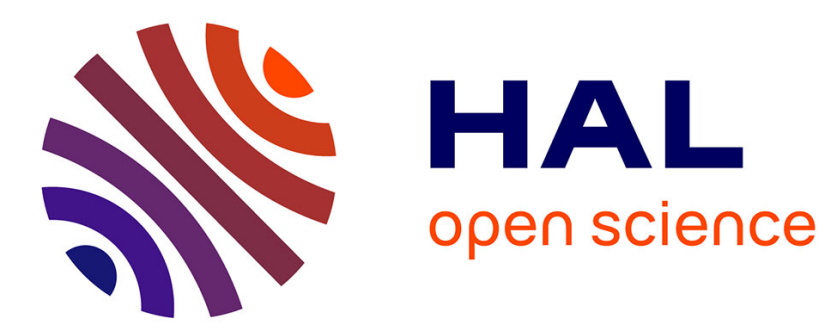

\title{
Effect of elaboration velocity on magnetic properties of melt spun amorphous metal ribbons
}

\author{
G. Le Gal, M. Henry, F. Varret
}

\section{To cite this version:}

G. Le Gal, M. Henry, F. Varret. Effect of elaboration velocity on magnetic properties of melt spun amorphous metal ribbons. Revue de Physique Appliquée, 1987, 22 (8), pp.729-734. 10.1051/rphysap:01987002208072900 . jpa-00245602

\section{HAL Id: jpa-00245602 https://hal.science/jpa-00245602}

Submitted on 1 Jan 1987

HAL is a multi-disciplinary open access archive for the deposit and dissemination of scientific research documents, whether they are published or not. The documents may come from teaching and research institutions in France or abroad, or from public or private research centers.
L'archive ouverte pluridisciplinaire HAL, est destinée au dépôt et à la diffusion de documents scientifiques de niveau recherche, publiés ou non, émanant des établissements d'enseignement et de recherche français ou étrangers, des laboratoires publics ou privés. 


\title{
Effect of elaboration velocity on magnetic properties of melt spun amorphous metal ribbons
}

\author{
G. Le Gal (*), M. Henry (*) (**) and F. Varret (*) \\ (*) Laboratoire de Spectrométrie Mössbauer, U.A. 807, Faculté des Sciences, Route de Laval, \\ 72017 Le Mans Cedex, France \\ (**) I.U.T. Département Génie Mécanique, 72017 Le Mans Cedex, France
}

(Reçu le 3 décembre 1986, révisé le 16 mars 1987, accepté le 5 mai 1987)

\begin{abstract}
Résumé. - L'aliage amorphe $\mathrm{Fe}_{74,7} \mathrm{Cr}_{3,8} \mathrm{P}_{8,7} \mathrm{C}_{10,7} \mathrm{Si}_{1,9}$ a été obtenu par hypertrempe sur roue sous forme de ruban avec des vitesses du substrat variant entre 20 et $46 \mathrm{~ms}^{-1}$. Les propriétés magnétiques des échantillons bruts de coulée sont étudiées par différentes techniques : la texture magnétique par Spectrométrie Mössbauer, l'aimantation, le champ coercitif et la température de Curie par mesures de cycles d'hystérésis à $50 \mathrm{~Hz}$. Les résultats expérimentaux ne font apparaître qu'une corrélation entre la largeur des rubans obtenus et leur texture magnétique.
\end{abstract}

\begin{abstract}
Fe}_{74.7} \mathrm{Cr}_{3.8} \mathrm{P}_{8.7} \mathrm{C}_{10.7} \mathrm{Si}_{1.9}$ amorphous alloy in ribbon shape have been obtained by melt spinning with substrate velocity in the range $20-46 \mathrm{~ms}^{-1}$. Magnetic properties of as-quenched samples are studied by different techniques : the ribbon's magnetic texture by Mössbauer spectroscopy, the magnetization, coercive field and Curie temperature by investigation of $\mathrm{B}-\mathrm{H}$ loops at $50 \mathrm{~Hz}$. The experimental results give evidence for correlation between ribbon width and magnetic texture only.
\end{abstract}

\section{Introduction.}

Interest in the properties of melt spun metallic glass ribbons is due to their numerous potential applications $[1,2]$; the major requirement for their industrial development is to produce well defined and reproducible ribbons.

Indeed, for any glassy material, the physical properties (magnetic, mechanical...) are known to depend on the cooling conditions [2]; namely the quenching velocity should have a major effect on the freezing temperature $T_{\mathrm{g}}$ and result in more or less departure from a stable structural state. For instance, we previously found [3] a sizeable effect of inhomogeneous quenching on the local magnetic texture (texture of ferromagnetic domains) via internal stresses and positive magnetostriction of the material : thicker areas under compressive stresses (due to earlier solidification) have preferential orientation perpendicular to the ribbon plane, while thinner areas under extensive stresses (later solidification) have a planar preferential orientation : this followed a model suggested by Kerr effect investigation of Fe$B$ glasses [4].

In addition to these short-range stresses, there should also exist long range quasi homogeneous stresses associated with the ideal quenching of the material. The maximum quenching velocity is expected to occur on the dull side, and hence to result in compressed surfaces and stretched bulk; as a mater of fact, this simple scheme has not yet been confirmed by the few literature data on conversion electron Mössbauer spectroscopy. So, the relative importance of hypothetical long range stresses remains unknown and, at least, should depend upon elaboration parameters.

Recently, the influence of substrate velocity on mechanical properties of amorphous alloy $\left(\mathrm{Fe}_{74.7} \mathrm{P}_{8.7} \mathrm{C}_{10.7} \mathrm{Si}_{1.9}\right.$ at. \%) has been studied [5] ; here we describe the magnetic properties of the same samples by using Mössbauer spectroscopy and hysteresis loops.

However, during the elaboration several parameters can simultaneously vary and it seems difficult to act on one parameter alone. Here for instance, the width and thickness of the ribbon varied, without any correlation with the substrate velocity, because the liquid flow could not be kept constant. Therefore the present data were analysed with respect to all three parameters. 
Also, a special emphasis was due to the Curie temperature, $T_{\mathrm{c}}$, often used as a control of structural relaxation [6], and suited to detect possible changes in $T_{\mathrm{g}}$.

\section{Experimental devices.}

The samples were obtained (B. De Guillebon, Pontà-Mousson Laboratoires) at different susbtrate velocities, in the range from 20 to $46 \mathrm{~ms}^{-1}$ (a stable casting of the ribbon then required adjusting other elaboration parameters). All measurementss are made on as-quenched. The ribbons mean widths were measured by using conventional mechanical means which give an overestimated value as previously said [7]. Here we accurately determined the mean thickness by weighting pieces of ribbon, on the assumption that specific mass is $\rho_{\mathrm{a}}=7.2 \mathrm{~g} \mathrm{~cm}^{-3}$, the latter value was obtained from the crystallized alloy's value $\rho_{\mathrm{c}}=7.4 \mathrm{~g} \mathrm{~cm}^{-3}$, reduced by the ratio $\rho_{\mathrm{a}} / \rho_{\mathrm{c}}=0.98$ usually used [8].

Mössbauer measurements have been carried out on a conventional Mössbauer spectrometer in transmission geometry using a single line source of ${ }^{57} \mathrm{Co}$ in rhodium. Mössbauer samples of $\pi \mathrm{cm}^{2}$ were made by setting ribbon pieces side by side. All spectra were taken at room temperature. The dull side of the ribbon was always facing the source (in order to keep deviation due to thickness and polarization effects comparable).

Hysteresis loops were obtained by a standard technique already described [9]. The amorphous sample consisted of one piece of ribbon $0.50 \mathrm{~m}$ long. All measurements were made at room temperature and with an A-C field $(50 \mathrm{~Hz})$.

The Curie temperature was measured by using an A-C induction method [10] with an applied field of about $10 \mathrm{Am}^{-1}$ at $50 \mathrm{~Hz}$. Samples were made of 10 packed pieces of ribbon $10 \mathrm{~mm}$ long. The heating rate was about $1^{\circ} \mathrm{C} \mathrm{s}^{-1}$.

\section{Results and discussion.}

3.1 Mössbauer StUdies. - By Mössbauer spectroscopy we have developed a method to determine the texture of magnetic domains, assuming that the hyperfine field distribution is the same for all the domains : the texture can be obtained from recording five spectra with different orientations between $\gamma$ beam and sample axes (Fig. 1) [3, 10, 11, 12]. Thus we determine three mean populations $N_{x}, N_{y}$, $N_{z}$ of spins respectively parallel to $\mathrm{O} X, \mathrm{O} Y, \mathrm{OZ}$. The five Mössbauer spectra for one sample are shown in figure 2.

The $A_{\text {sat }}$ spectrum was obtained with an applied field of $0.04 T$; the dotted line is the experimental spectrum and the full line corresponds to the fit with a hyperfine field discrete distribution, whose shape is given in figure 3 . The measured mean hyperfine

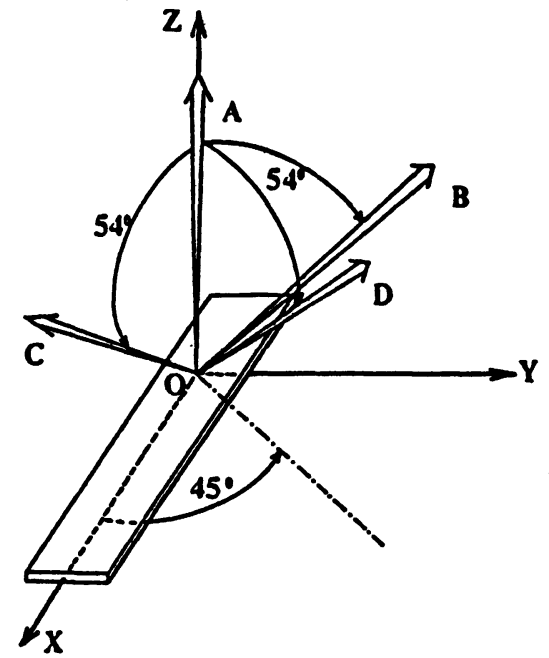

Fig. 1. - Orientation of $\gamma$ beam and set of principal axes, needed for magnetic texture determination [7].

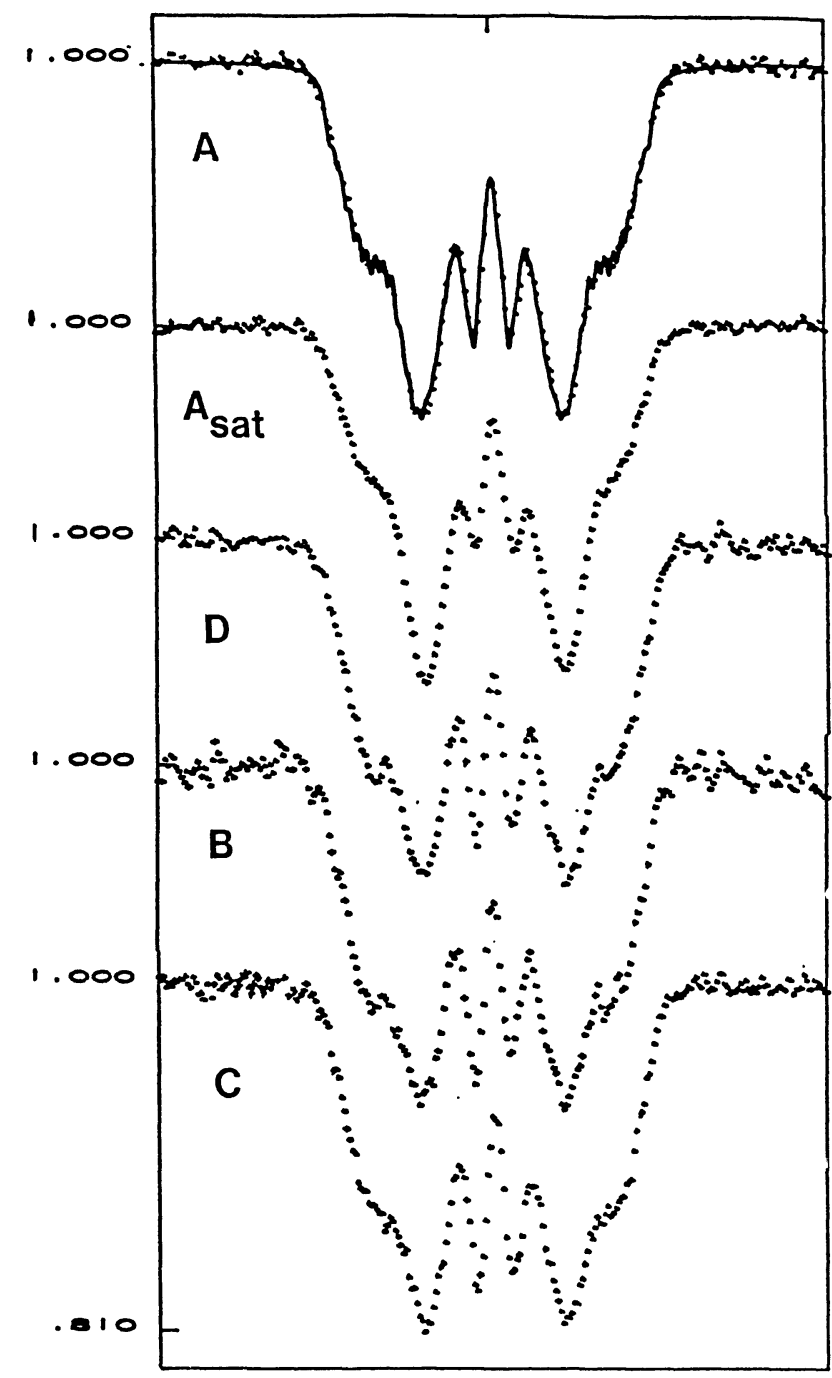

Fig. 2. - Mössbauer spectra at room temperature (sample corresponding to $27 \mathrm{~ms}^{-1}$ substrate velocity).

field did not vary through the samples; results on magnetic texture are given in table $\mathrm{I}$. 


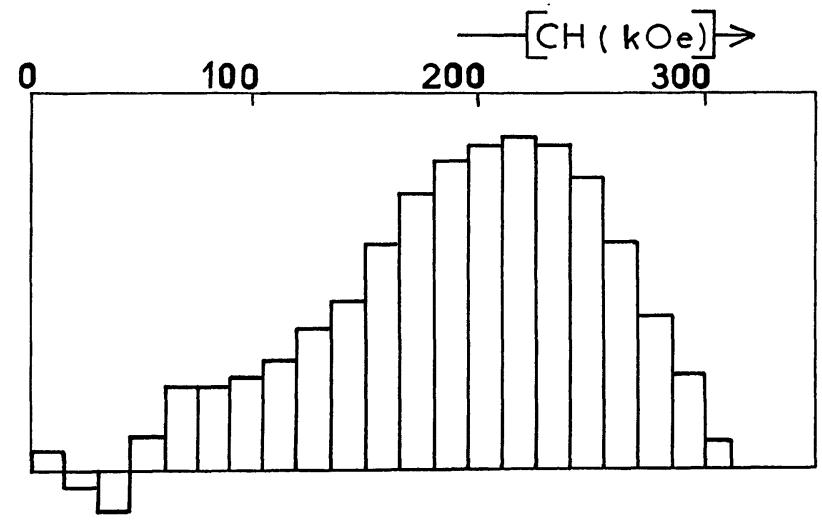

Fig. 3. - Hyperfine field distribution from spectrum A (Fig. 2).

3.2 DATA ANALYSIS. - All samples give $N_{x}+N_{y}>0.8$ which leads to the conclusion that the ribbons have an easy plane of magnetization $(\mathrm{O} X$, $O Y$ ). This may be due to both demagnetizing field and residual stresses in the as- quenched state [3]. $N_{z}$ is plotted versus substrate velocity and ribbon width in figure $4 \mathrm{a}$ and $4 \mathrm{~b}$ respectively : this does not give evidence for correlation with $N_{z}$ values. There-
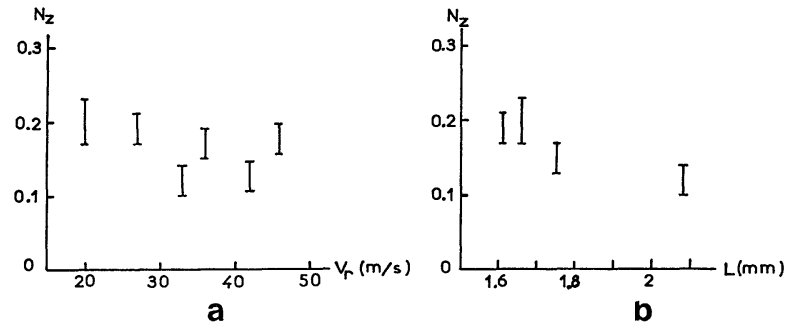

Fig. 4. - a) $N_{z}$ versus substrate velocity b) $N_{z}$ versus ribbon width. fore we have systematically searched for possible correlation according to a multilinear law :

$$
N_{i}=f(v, t, w)=k_{v}^{i} v+k_{t}^{i} t+k_{w}^{i} w+k_{0}^{i}
$$

( $i=x, y, z ; v, t, w$ stand for velocity, thickness, width respectively; $k_{0}^{i}$ are constants).

Taking into account that $N_{x}+N_{y}+N_{z}=1$, it follows that

$$
\sum_{i}\left(k_{v}^{i}\right)=\sum_{i}\left(k_{t}^{i}\right)=\sum_{i}\left(k_{w}^{i}\right)=0
$$

and

$$
\sum_{i}\left(k_{0}^{i}\right)=1 .
$$

Results of least squares fits are given in table II.

We observe that, within statistical deviations, $N_{y}$ is independent of all parameters : $N_{y}=$ $0.42(0.005)$

$N_{x}$ and $N_{z}$ just depend on width :

$$
\begin{aligned}
& N_{x}=0.12 \mathrm{w}+0.20 \\
& N_{z}=-0.14 \mathrm{w}+0.40
\end{aligned}
$$

Taking all standard deviations into account, (1) and (2) are verified, so that the present multilinear analysis is statistically relevant.

3.3 Discussion. - The correlation between $N_{z}$ population and ribbon width may be explained by the «edge effect " reported in [3], due to earlier solidification of the edges. Here the relative importance of edges decreases with increasing width, and therefore results in a smaller $N_{z}$ (as observed).

On the other hand, these data do not follow a static model of demagnetizing field, which should give in any case $N_{x}>N_{y}>N_{z}$; if indeed $N_{z}$ is always the smallest population, the balance between $N_{x}$ and $N_{y}$ results from a more subtle competition

Table I. - Geometrical data and magnetic texture for various substrate velocities. (*) Standard deviation $=0.02$, unless otherwise-specified [11]. $V=$ linear substrate velocity. $Q=$ volumic outlet $(Q=$ wtV). $N_{i}=$ spin population along $i$ axis.

\begin{tabular}{|l|c|c|c|c|c|c|}
\hline$V\left(\mathrm{~ms}^{-1}\right)$ & 20 & 27 & 33 & 36 & 42 & 46 \\
\hline$t(\mu \mathrm{m})$ & 31.4 & 33.0 & 25.9 & 21.9 & 20.6 & 18.7 \\
\hline$w(\mathrm{~mm})$ & 1.71 & 1.64 & 2.08 & 1.63 & 1.75 & 1.63 \\
\hline$Q\left(\mathrm{~mm}^{3} . \mathrm{s}^{-1}\right)$ & 1075 & 1460 & 1780 & 1285 & 1515 & 1400 \\
\hline$N_{z}(*)$ & $0.20(0.03)$ & 0.19 & 0.12 & 0.17 & 0.15 & 0.175 \\
\hline$N_{x}\left(^{*}\right)$ & $0,37(0.04)$ & 0.39 & 0.46 & 0.42 & 0.43 & 0.42 \\
\hline$N_{y}\left(^{*}\right)$ & $0.43(0.04)$ & 0.43 & 0.42 & 0.41 & 0.40 & 0.405 \\
\hline
\end{tabular}


Table II. - Multilinear analysis using least square fit : $N_{i}=k_{v} v+k_{t} t+k_{w} w+k_{0}$ in brackets : standard deviation.

\begin{tabular}{|c|c|c|c|c|}
\hline & $k_{v}\left(\mathrm{~ms}^{-1}\right)$ & $k_{t}\left(\mu \mathrm{m}^{-1}\right)$ & $k_{w}\left(\mathrm{~mm}^{-1}\right)$ & $k_{0}$ \\
\hline$N_{z}$ & $-0.001(0.002)$ & $\begin{array}{c}0.0002(0.002) \\
-\end{array}$ & $\begin{array}{l}-0.14(0.03) \\
-0.14(0.05)\end{array}$ & $\begin{array}{l}0.46(0.13) \\
0.40(0.08)\end{array}$ \\
\hline$N_{x}$ & $\begin{array}{c}0.002(0.002) \\
-\end{array}$ & $\begin{array}{c}-0.0001(0.003) \\
-\end{array}$ & $\begin{array}{l}0.13(0.04) \\
0.12(0.07)\end{array}$ & $\begin{array}{l}0.11(0.16) \\
0.20(0.11)\end{array}$ \\
\hline$N_{y}$ & $\begin{array}{c}0.002(0.002) \\
- \\
-\end{array}$ & $\begin{array}{c}-0.002(0.004) \\
- \\
-\end{array}$ & $\begin{array}{c}-0.002(0.03) \\
0.008(0.04) \\
-\end{array}$ & $\begin{array}{l}0.54(0.12) \\
0.40(0.06) \\
0.42(0.005)\end{array}$ \\
\hline
\end{tabular}

involving anisotropy of the planar stresses and does not allow to prodict any correlation with the experimental quenching conditions.

\subsection{MACROSCOPIC MAGNETIC PROPERTIES.}

3.4.1 Saturation magnetization $\left(B_{\mathrm{s}}\right)$. - By using a vibrating sample magnetometer we have determined the saturation magnetization. Numerical data are given using $\rho_{\mathrm{a}}=7.2 \mathrm{~g} \mathrm{~cm}^{-3}$ for all the samples (see Sect. 2).

Because of constant chemical composition a constant $B_{\mathrm{s}}$ is expected. On table III we give the

Table III. - Saturation magnetization $\left(B_{s}\right)$ from vibrating sample magnetometer data.

\begin{tabular}{|c|l|l|l|l|}
\hline$V\left(\mathrm{~ms}^{-1}\right)$ & 27 & 33 & 36 & 46 \\
\hline$B_{s}(T)$ & 1.25 & 1.28 & 1.28 & 1.26 \\
\hline
\end{tabular}

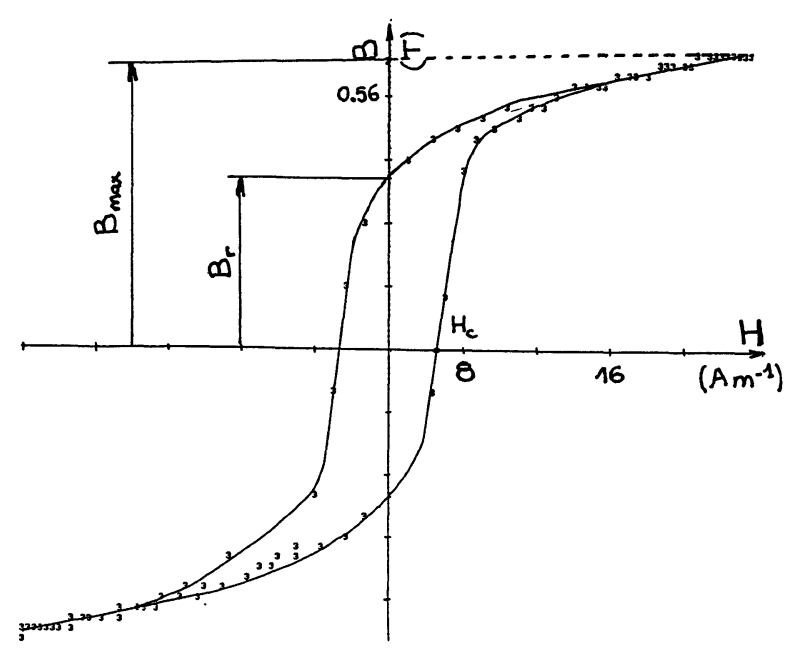

Fig. 5. - Hysteresis B-H loops (sample $v=36 \mathrm{~ms}^{-1}$ ). measured $B_{\mathrm{s}}$ for 4 samples, which are consistent with a constant value :

$$
B_{\mathrm{s}}=(1.27 \pm 0.02) T .
$$

3.4.2 Hysteresis loop measurements. - By applying an A-C field up to $750 \mathrm{Am}^{-1}$, the recorded hysteresis
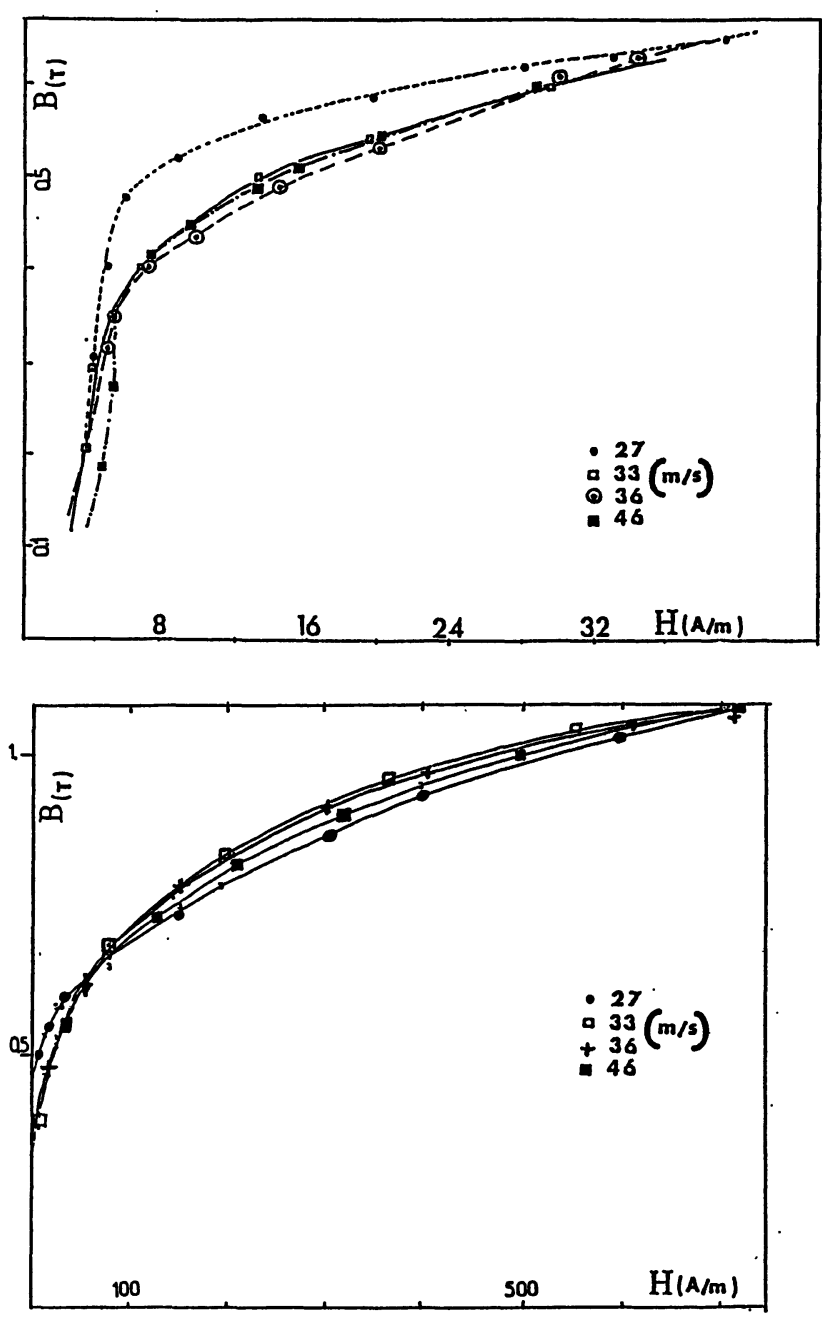

Fig. 6. - a) $B(H)$ curve for weak A-C field $\left(<40 \mathrm{Am}^{-1}\right)$ b) $b(H)$ curve for large A-C field (up to $\left.800 \mathrm{Am}^{-1}\right)$. 
loops provided magnetization and permeability data. All samples give B-H curves with typical rounded shape (Figs. 5-6), but varying from a sample to another.

The relative permeability $\mu_{\mathrm{r}}$ of the as-quenched ribbons reaches high values $\left(\sim 7 \times 10^{4}\right)$ for rather small applied fields $H_{\mathrm{c}}=5.2 \pm 0.4 \mathrm{Am}^{-1}$.

Data given in table IV are average values for $0.50 \mathrm{~m}$ long samples : indeed ribbons give variable data along their longitudinal axis because of variable section : this prevents from estimating relevantly the accuracy of the mean value (it is not possible to use shorter samples, for instance $0.05 \mathrm{~m}$ long, because of demagnetizing field).

Table IV. - Coercitive field $\left(H_{c}\right)$ and squareness $\left(B_{r} / B_{\max }\right)$ measurements from $B-H$ loops at $50 \mathrm{~Hz}$ in $A-C$ field of $40 \mathrm{Am}^{-1}$ (Fig. 6).

\begin{tabular}{|l|l|l|l|l|l|l|}
\hline$V(\mathrm{~m} / \mathrm{s})$ & 20 & 27 & 33 & 36 & 42 & 46 \\
\hline$H_{\mathrm{c}}(\mathrm{A} / \mathrm{m})$ & 6.8 & 6.2 & 5.1 & 5.8 & 5.5 & 5.9 \\
\hline$\frac{B_{\mathrm{r}}}{B_{\max }}$ & 0.72 & 0.77 & 0.46 & 0.59 & 0.53 & 0.59 \\
\hline$\mu_{\mathrm{m}}\left(10^{3}\right)$ & 62 & 48 & 58 & 50 & 43 & 43 \\
\hline
\end{tabular}

Searching again for multilinear correlations (see Sect. 3.2) we have analysed $H_{\mathrm{c}}$ and $B_{\mathrm{r}} / B_{\max }$ data ; results are given in table $\mathrm{V}$. An influence of ribbon thickness and with on magnetic properties can be detected. The major effect is due to width, so that the widest ribbon has smallest values for $N_{z}$, $H_{\mathrm{c}}, B_{\mathrm{r}} / B_{\max }$, but largest value for $\mu_{\mathrm{r}}$.

A more accurate investigation, namely of $\mu_{\mathrm{r}}$ would require ribbons of more constant geometrical shape.

3.4.3 Curie Temperatures. - For all samples, the Curie temperatures are similar, within a narrow range : $T_{\mathrm{c}}=238 \pm 0.5^{\circ} \mathrm{C}$.
Previous study [10] on amorphous

$$
\mathrm{Fe}_{72.5} \mathrm{Cr}_{6.5} \mathrm{P}_{13.2} \mathrm{C}_{7.8}
$$

during annealing showed that $T_{\mathrm{c}}$ and a « fictitious glass temperature » $T_{\mathrm{gf}}$ were correlated, according to :

$$
\frac{\Delta T_{\mathrm{c}}}{\Delta T_{\mathrm{gf}}}=0.05
$$

We conclude that the total variation of $T_{\mathrm{g}}$ within the set of samples under study is restricted to: $\Delta T_{\mathrm{g}}<20^{\circ} \mathrm{C}$.

3.4.4 Discusion. - The values of $T_{\mathrm{c}}$ show that the different substrate velocities did not lead to large variations of $T_{\mathrm{g}}$ : therefore we conclude that the quenching velocity remained nearly the same, in agreement with the lack of variation of the mean hyperfine; this may reflect the constancy of heat transfer from the liquid puddle to the substrate.

Then, the differences reported in the present paper do not support the idea of substantial change of the structural state as a function of substrate velocity and only have an extrinsic character.

A simple idea, based on the quasi homogeneous model of stresses, is that low-field magnetization is due to "easy spin " belonging to populations $N_{x}, N_{y}$; the magnetization curve depends both on the values of the populations and on their anisotropies (probably smeared over several orders of magnitude, according to the magnetization curves presented in Fig. 6b) ; therefore there is no way to correlate discrete populations and smooth magnetization curves. There is no more correlation between texture and $B_{\mathrm{r}}$, whose experimental values do not follow $N_{x}$ or $N_{x}+N_{y}$ value (but the reverse trend). So « easy » or « hard » spins do not strictly correspond to populations $N_{x, y}$ or $N_{z}$; although the easiest spins certainly belong to $N_{x}$ and the hardest to $N_{z}$ (with respect to an external field applied along $O X)$.

However the magnetization curves can tell how easy are the easy spins (in low field region) and how

Table V. - Multilinear analysis using least squares fit: $H_{c}\left(\right.$ or $\left.B_{r} / B_{\max }\right)=k_{v} v+k_{t} t+k_{w} w+k_{0}$ in brackets : standard deviation.

\begin{tabular}{|c|c|c|c|c|}
\hline \multirow{3}{*}{$H_{\mathrm{c}}$} & $k_{v}\left(\mathrm{sm}^{-1}\right)$ & $k_{t}\left(\mu \mathrm{m}^{-1}\right)$ & $k_{w}\left(\mathrm{~mm}^{-1}\right)$ & $k_{0}$ \\
\cline { 2 - 5 } & $0,03(0,04)$ & $0,15(0,08)$ & $-2,1(0,6)$ & $4,3(4)$ \\
\cline { 2 - 5 } & - & $0,09(0,02)$ & $-2,3(0,5)$ & $7,5(1)$ \\
\hline \multirow{2}{*}{$\frac{B_{\mathrm{r}}}{B_{\max }}$} & $-0,002(0,002)$ & $0,01(0,004)$ & $-0,52(0,05)$ & $1,3(0,2)$ \\
\cline { 2 - 5 } & - & $0,013(0,001)$ & $-0,51(0,05)$ & $1,17(0,08)$ \\
\hline
\end{tabular}


hard are the hard spins. The easiness of easy spins follows the isotropy of stresses in the ribbon plane, more or less correlated with the magnitude of short range stresses; the relevant parameter here is the maximum susceptibility (Tab. III), whose experimental values increase with increasing thickness and decreasing width. The hardness of hard spins combines short-range and long-range stresses and monitors the remainder of the magnetization curve ; according to figure $6 \mathrm{~b}$, it varies at the reverse of lowmagnetization, namely increases for decreasing thickness or increasing width.

The role of thickness on long range stresses is obvious, since a thicker ribbon will superimpose the shrinking effects due to solidification of successive layers. The role of thickness on short range stresses might involve the dwell time of the ribbon under the liquid puddle; however little is known on the mechanics and thermodynamics of the puddle, and so many uncontrolled parameters involved that any more definitive conclusion would be rather bold.

\section{Conclusion.}

In the present set of experiments, magnetic properties were more or less correlated with substrate velocity ; the magnetic texture was neatly correlated with the ribbon width, and this effect was explained in terms of "edge effect»: the coercive field and magnetic permeability were sizeably depending on width and thickness of the ribbon.

On the other hand, the observation of the same $T_{\mathrm{c}}$ and hyperfine field for all samples lead to the conclusion that no sizeable change in structural state and quenching velocity was obtained, so that the variations reported above are typical extrinsic effects, probably related with the size and stability of the liquid puddle.

\section{Acknowledgment.}

The authors would like to thank M. B. de Guillebon (Centre de Recherche de Pont-à-Mousson) for providing the samples.

\section{References}

[1] Fournier, P., Henry, M., Rev. Gen. Electr. 5 (1983) 314.

[2] Les amorphes métalliques (Editions de Physique, Paris) 1983.

[3] Bourrous, M., Henry, M., Greneche, J. M., VARRET, F., R.Q.M. 5 (Ed. Varlimont) 1985, p. 1231.

[4] Kronmuller, H., Atomic Energy Review (1981) 255.

[5] Allemand, J. P., Fouquet, F., Perez, J., DE Guilllebon, B., Rev. Metall. (Paris) Part 19 (1985) 466.

[6] Kudo, T., Egami, T., LiebermanN, H. H., RQM 4 (Sendai) 1981, p. 1187-1190.

[7] Henry, M., Bourrous, M., Varret, F., FourNIER, P., J. Mater. Sci. 19 (1984) 1000-1006.

[8] Spaepen, F., J. Non Cryst. Solids 31 (1978) 207-221.
[9] Henry, M., Greneche, J. M., Bourrous, M., Varret, F., Rev. Métall. (Paris) Part 15 (1985) 233-246.

[10] Bourrous, M., Thèse 1985, Le Mans.

[11] Greneche, J. M., Henry, M., VArret, F., J. Mag. Mag. Mat. 26 (1982) 153-156.

Greneche, J. M., Henry, M., Varret, F., Proceedings of I.C.A.M.E. (Jaïpur 1981), p. 900 902 et p. 908-911.

[12] Greneche, J. M., Varret, F., J. Phys. C. 15 (1982) 5333-5344.

[13] Greneche, J. M., Varret, F., Solid State Commun. 54 (1985) 985.

[14] VArret, F., Hyperfine Interactions 27 (1986) 313316.

VARRET, F., Hyperfine Interactions 30 (1986) 135144. 